\title{
Novel insights in dimethyl carbonate-based extraction of polyhydroxybutyrate (PHB)
}

\author{
Beatrice Mongili ${ }^{1+}$, Annalisa Abdel Azim² ${ }^{*}$ (D, Silvia Fraterrigo Garofalo ${ }^{1}$, Esperanza Batuecas ${ }^{3}$, Angela Re$^{2}$,
} Sergio Bocchini ${ }^{2}$ and Debora Fino ${ }^{1}$

\begin{abstract}
Background: Plastic plays a crucial role in everyday life of human living, nevertheless it represents an undeniable source of land and water pollution. Polyhydroxybutyrate (PHB) is a bio-based and biodegradable polyester, which can be naturally produced by microorganisms capable of converting and accumulating carbon as intracellular granules. Hence, PHB-producing strains stand out as an alternative source to fossil-derived counterparts. However, the extraction strategy affects the recovery efficiency and the quality of PHB. In this study, PHB was produced by a genetically modified Escherichia coli strain and successively extracted using dimethyl carbonate (DMC) and ethanol as alternative solvent and polishing agent to chloroform and hexane. Eventually, a Life Cycle Assessment (LCA) study was performed for evaluating the environmental and health impact of using DMC.

Results: Extraction yield and purity of PHB obtained via DMC, were quantified, and compared with those obtained via chloroform-based extraction. PHB yield values from DMC-based extraction were similar to or higher than those achieved by using chloroform ( $\geq 67 \%)$. To optimize the performance of extraction via DMC, different experimental conditions were tested, varying the biomass state (dry or wet) and the mixing time, in presence or in absence of a paper filter. Among 60, 90, 120 min, the mid-value allowed to achieve high extraction yield, both for dry and wet biomass. Physical and molecular dependence on the biomass state and solvent/antisolvent choice was established. The comparative LCA analysis promoted the application of DMC/ethanol rather than chloroform/hexane, as the best choice in terms of health prevention. However, an elevated impact score was achieved by DMC in the environmentallike categories in contrast with a minor contribution by its counterpart.

Conclusion: The multifaceted exploration of DMC-based PHB extraction herein reported extends the knowledge of the variables affecting PHB purification process. This work offers novel and valuable insights into PHB extraction process, including environmental aspects not discussed so far. The findings of our research question the DMC as a green solvent, though also the choice of the antisolvent can influence the impact on the examined categories.
\end{abstract}

Keywords: Polyhydroxybutyrate, Extraction yield, Solvent-based extraction, Dimethyl carbonate, Multifactorial experiments, LCA analysis

\footnotetext{
*Correspondence: annalisa.abdelazim@iit.it

${ }^{\dagger}$ Beatrice Mongili and Annalisa Abdel Azim are first authors

${ }^{2}$ Centre for Sustainable Future Technology (CSFT), Italian Institute of Technology, Via Livorno 60, 10144 Turin, Italy

Full list of author information is available at the end of the article
}

\section{Background}

Plastics meet countless needs in our daily life, with their applications in packaging, building and constructions, automotive, household, labware, hospital equipment and electronic to cite only some examples. Current plastic production is about 348 million tonnes to answer the market demand, and this number will double in the next decade on the base of market projection [1]. 
Plastics are petroleum-derived materials and represent a vast source of greenhouse gasses (GHG) emissions during all their life cycles. The rising demand for plastic materials will increment the global emission release up to $6.850 \mathrm{Gt}$ of $\mathrm{CO}_{2}$-equivalent by 2050 [2]. Hence the production and consumption of fossil-based plastics must be reduced to leave the place to more sustainable materials. Beyond recycling plastics and using renewable energy for plastics generation, bio-based polymers embody an alternative to conventional plastics. Indeed, if about the $70 \%$ of plastic demand would be fulfilled with bio-based plastic, 241-316 Mt of $\mathrm{CO}_{2}$-equivalent would be avoided [3]. Polyhydroxyalkanoates (PHAs) are biologically produced plastic-like material acting as a sink of carbon and reducing equivalent for some microbial species $[4,5]$. Currently, more than 90 genera of bacteria and some haloarchaea species have been identified as PHAs producers [6]. PHA general structure consists of a monomer of 3-hydroxy fatty acids, where the residual group length can vary between $C_{1}$ to $C_{14}$ [7]. PHAs are completely compostable and biocompatible, resistant to hydrolysis, UV irradiation, insoluble in water and controllable in their thermal and mechanical behaviour and prone to versatile functionalization [8-10]. These properties make PHAs central precursors supportive for the creation of tailor-made products in manifold applications [7]. Among the different types of PHAs, poly-3-hydroxybutyrate (PHB) is a short chain polymer hosting a methyl group at $\mathrm{C} 3$ position, which confers to the polymer high crystallinity and rigidity. As PHB is stored within the microbial cytoplasm as granules $(0.12$ to $0.5 \mu \mathrm{m})$, the polymer recovery represents a technological barrier to its application and a high-cost procedure, which accounts for $50 \%$ of the final polymer price. Therefore, many efforts have been employed in the extraction and purification processes, among which solvent-based extraction is the most used recovery strategy. Chloroform is the most applied solvent because of its high PHB extraction power. Several studies report values of recovery up to $95 \%$ [11-14]. The addition of hexane as anti-solvent improved PHB purity and recovery as reported by Fei et al. [15]. However, the use of those two toxic chemicals negatively impacts on human and environmental protection. Therefore, it is worth seeking alternative chemicals and extraction strategies, which could achieve satisfactory balance in terms of safety and efficiency. Among those, dimethyl carbonate (DMC) has become increasingly important in the chemical industry, mainly because of its versatility as reagent and solvent, and its low toxicity for human health $[16,17]$. DMC is an acyclic alkyl carbonate industrially produced by catalytic oxidative carbonylation of methanol through a green process developed by Enichemand UBE Industries (JP) [18]. This solvent is fully biodegradable, non-irritating and nonmutagenic either by contact or by inhalation. DMC owns negligible reactivity in the formation of photochemical smog. Hence it has been excluded from the list of volatile organic compounds $[19,20]$. For all the above-mentioned reasons, DMC has been selected as an alternative solvent to chloroform commonly applied for PHB extraction.

The present study investigates the application of DMC on PHB-rich biomass by varying the extraction procedure on the base of three factors: biomass, filter and mixing time (Fig. 1). In this study we evaluated the extraction efficiency of DMC on both pre-treated (i.e. dry) and untreated biomass (i.e. wet). Biomass pre-treatments, such as heating, freeze-drying, sonication or chemical oxidation reduce the integrity of microbial cell membrane, in favour of an incremented PHB extraction yield $[13,21]$. However, pre-treating the biomass can affect the physical properties of the polymer as for chemical oxidation, which is well known to decrease the molecular weight of the polymer [22] as well as for lyophilization and heating which cause polymer chains rearrangement with a consequent variation of its crystallinity [23]. Furthermore, the application of those pre-treatments also requires an investment in additional material, operational energy, and costs. By the introduction of a paper filter, we attempted to: (1) improve the purity of the PHB without affecting its properties, (2) improve the manageability of the extraction procedure in a lab-scale context. Indeed, the filter was initially conceived as a physical barrier between biomass and solvent phase to enable a tidy separation of the two in a small volume of reaction and achieve highly pure PHB [15]. However, the evidence of our experiments did not support the filter application, but rather highlighted the efficacy of using wet biomass instead of the dry one. The mixing time, defined as the time of contact between biomass and solvent, is the third variable we decided to investigate. The selection of the optimal mixing time is a critical point for solvent-based extraction of PHB as showed by Fiorese et al. [24]. Here the importance of mixing time was also analysed in relation to the biomass and the filter with regard to PHB extraction yield, purity, and molecular properties.

In order to address all the purposes of the present study, a genetically modified Escherichia coli strain hosting PHB biosynthetic pathway was selected. The application of an engineered $E$. coli rather than a natural PHB-producing bacterium is reliant on the fact that $E$. coli is a well-known microorganism whose metabolism and cultivation are characterized in detail. $E$. coli is easy to handle, it can ensure fast growth rates despite the application scale, it guarantees high yield of biomass and PHB accumulation [25-28]. Moreover, E. coli is a Gram-negative like most of the natural 


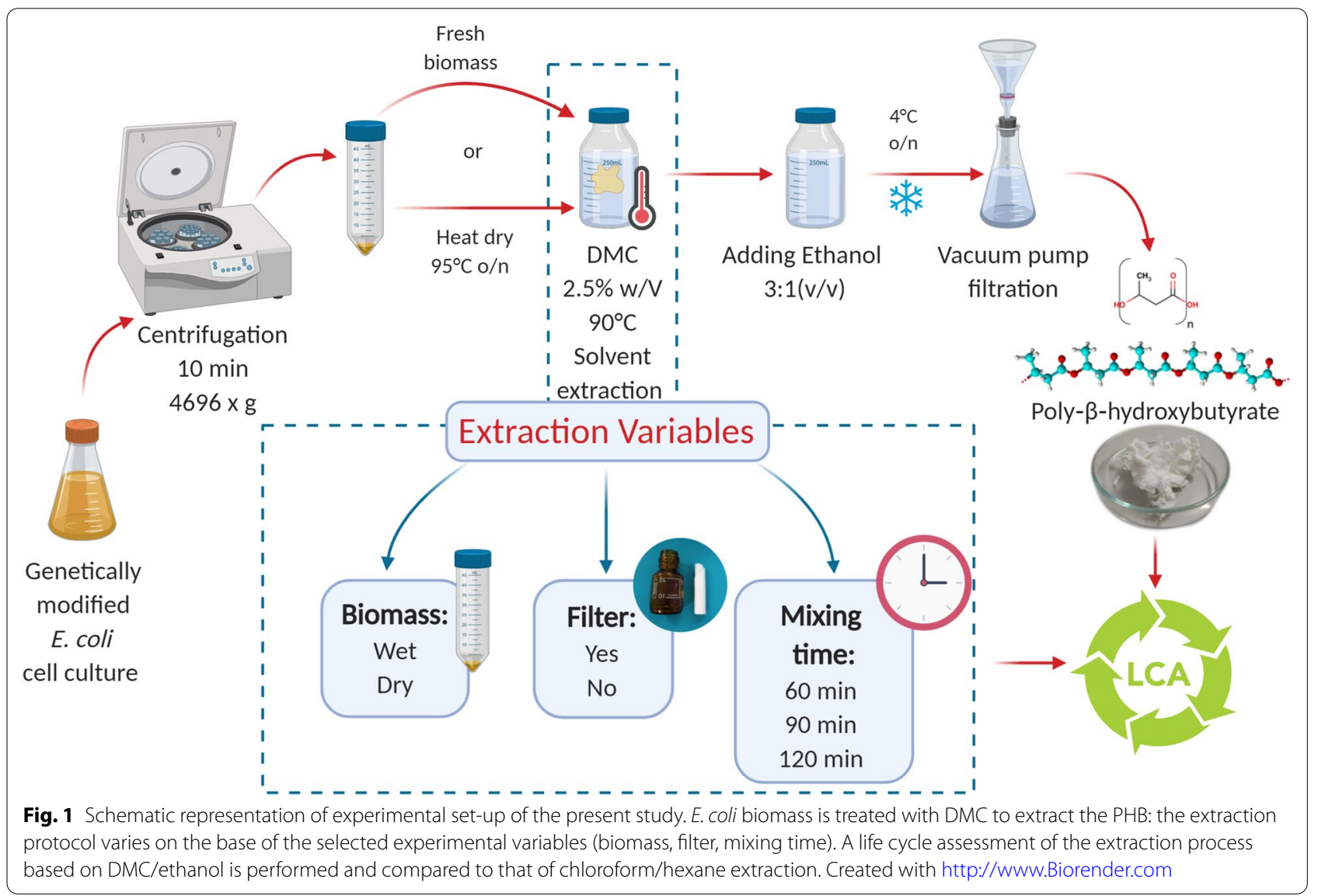

PHB producers (e.g. Cupriavidus necator or Azotobacter vinelandii) with which it shares the same cellular membrane structure. Finally, it is worthwhile noting that, unlike natural PHB-producing strains, E. coli does not own depolymerase activity, which makes it a valid candidate for being a model microorganism for PHA recovery study.

In our research, the extraction protocol was adapted to the laboratory scale and conditions, which are quite different from the industrial approach. Many studies reported the extraction procedure in a lab-scale frame, but only few investigated the life cycle of the DMC [29]. Recently, the chemical industry has shown an increased interest in Life Cycle Assessment (LCA). However, much uncertainty still exists about the environmental impacts of solvents, especially in lab-scale setups [30]. For this reason, each experiment conducted in this study was accompanied by an LCA analysis. A complete scheme of the design at the base of our study is available as Fig. 1. If on the one hand, the present work addresses the optimization of DMC-based extraction to maximize the PHB recovery and purity, on the other hand, it aims at assessing the impact at many levels of DMC applied as green solvent a priori. In conclusion, this study traces the guidelines to select the optimal conditions for a more sustainable PHB extraction.

\section{Results and discussion}

\section{PHB extraction yield and purity}

Results show that DMC-based extraction can compete with the standard method based on chloroform (Fig. 2).

In terms of extraction yield, the DMC-based extraction is comparable to that based on chloroform when the mixing time is equal to $90 \mathrm{~min}$ both on wet and dry biomass (Fig. 2a). When processing wet biomass, the extraction yields assume always values above $67 \%$, independently on the mixing time. Mixing time seems to acquire specific importance when the DMC extraction occurs on dry biomass. Moreover, a contact time of $90 \mathrm{~min}$ is optimal, resulting in a rise of the extraction yield $(68.67 \pm 1.66 \%)$. Table 1 compares the extraction yields of this work and other publicly available studies.

Aramvash et al. [14] recorded an extraction yield of 96\% using butyl acetate on wet biomass for a contact time of $30 \mathrm{~min}$ (Table 1). Similar values were also found in McChalicher et al. [31] and Manangan and Shawaphun [11], using propylene carbonates and dimethyl formamide as solvents, respectively (Table 1), but with a very 


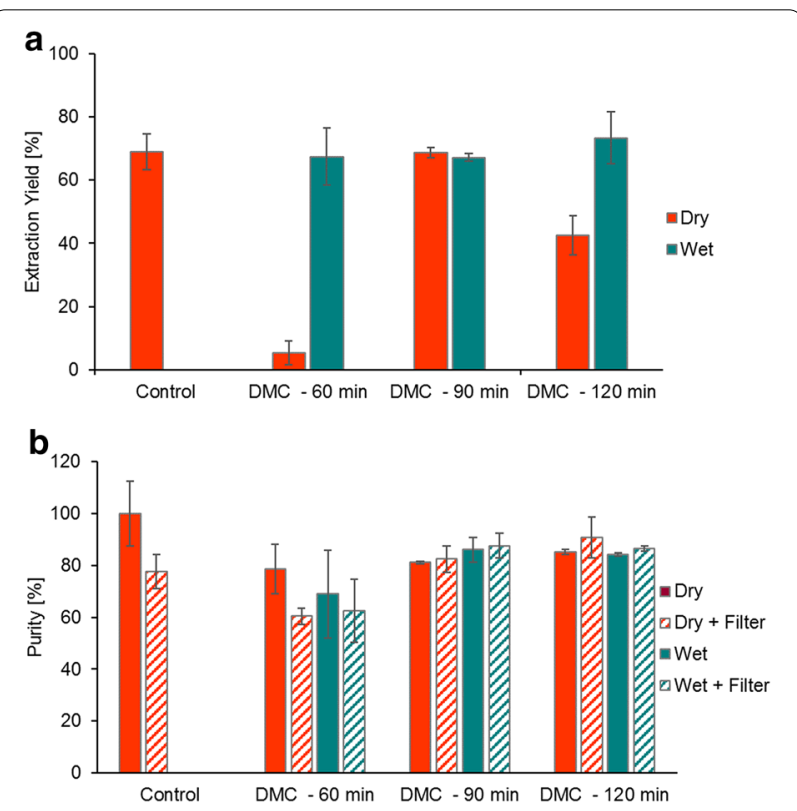

Fig. 2 PHB extraction yield (a) and purity (b) of samples extracted by chloroform as the standard method (control) and by DMC at different mixing times. Dry and wet biomass are in red and green, respectively; the presence of the filter is indicated by the dashed bars

short mixing time concerning the former. Our results indicate that a contact time of $60 \mathrm{~min}$ is not enough for extracting the PHB from dry biomass, with a final yield of $5.3 \pm 3.7 \%$. The same extraction protocol, except for the lyophilized biomass and the application of a mixed culture, is applied in Samorì et al. [32] who reported a PHB extraction yield of $20 \pm 1 \%$ (Table 1). Such difference in results could depend not only on the mixing time, but also on the initial biomass state (lyophilized or dried), and the utilization of different PHB-producing strains. On the other hand, a mixing time of $120 \mathrm{~min}$ on dry samples, results to be excessive since the extraction yield drops to $42.5 \pm 6.2 \%$. Although not showed here, results of the extraction yield in presence of the filter are available at
Additional file 1: Table S1 and are discussed in the next paragraph. Concerning the PHB purity (Fig. 2b), chloroform extraction gave a value of $100 \pm 12.5 \%$, which drop to $88.3 \pm 6.7 \%$ when adding the filter. The PHB purity values are nearly similar in DMC-based extraction at 90 and $120 \mathrm{~min}$, regardless of the biomass and filter (Additional file 1: Table S1). Even though the use of a paper filter should simplify the separation between polymer and biomass and favour PHB collection [15], the results collected in this study (Fig. 2 and Additional file 1: Table S1) do not support the use of the filter as real improvement in the purification process in the specific frame of our work. A possible explanation could be found in the different application scale of Fei et al. [15] and the present study, large and small scale, respectively. Another point might be the leading forces involved in PHB separation, i.e. pressure and gravity in Fei et al. [15] with respect to the sole diffusion through the filter pores toward the boiling solvent. As a matter of time, the purity decreases when biomass and solvent are mixed for $60 \mathrm{~min}$, which may indicate that a shorter mixing time is less incisive on impurities breakup than longer contact time [24]. However, considering the high standard deviation, this variation is not statistically significant, and it cannot be associated with the wet state of the biomass with certainty.

\section{Combined effect of experimental factors}

The individual and combined effect of the investigated experimental variables-paper filter, pellet, and mixing time-on the extraction yield was evaluated through regression analysis.

Wet pellet and increased mixing time show a statistically significant positive influence on extraction yield, whereas no statistically significant dependence of PHB extraction yield on the filter was detected $(\alpha=1 \%)$, as shown in Fig. 3a. The impact of experimental factor combinations involving the filter did not turn out to be statistically significant except for the interaction of the filter with pellet, which is highlighted in the data clustering

Table 1 PHB extraction yield depending on the extraction process

\begin{tabular}{llll}
\hline Biomass & Extraction process & Extraction yield (\%) & References \\
\hline Dry & Chloroform & $39 \pm 2$ & {$[11]$} \\
Dry ${ }^{\mathrm{a}}$ & Dimethyl formamide, solid-liquid extraction & $68 \pm 4$ & {$[11]$} \\
Lyophilized & 1,2 -Propylencarbonate, $120{ }^{\circ} \mathrm{C}$ for 15 min & $96 \pm 1$ & {$[31]$} \\
Wet & Butyl acetate, $103^{\circ} \mathrm{C}$, for 30 min & $20 \pm 1$ & {$[14]$} \\
Lyophilized & Dimethyl carbonate, $90^{\circ} \mathrm{C}$ for 60 min & $69 \pm 2$ & This study \\
Dry & Dimethyl carbonate, $90^{\circ} \mathrm{C}$ for 90 min & $73 \pm 8$ & This study \\
Wet & Dimethyl carbonate, $90^{\circ} \mathrm{C}$ for 120 min & $69 \pm 6$ & This study \\
Dry & Chloroform, $60^{\circ} \mathrm{C}$ for 120 min & & \\
\hline
\end{tabular}

a Pre-treated with ethanol 


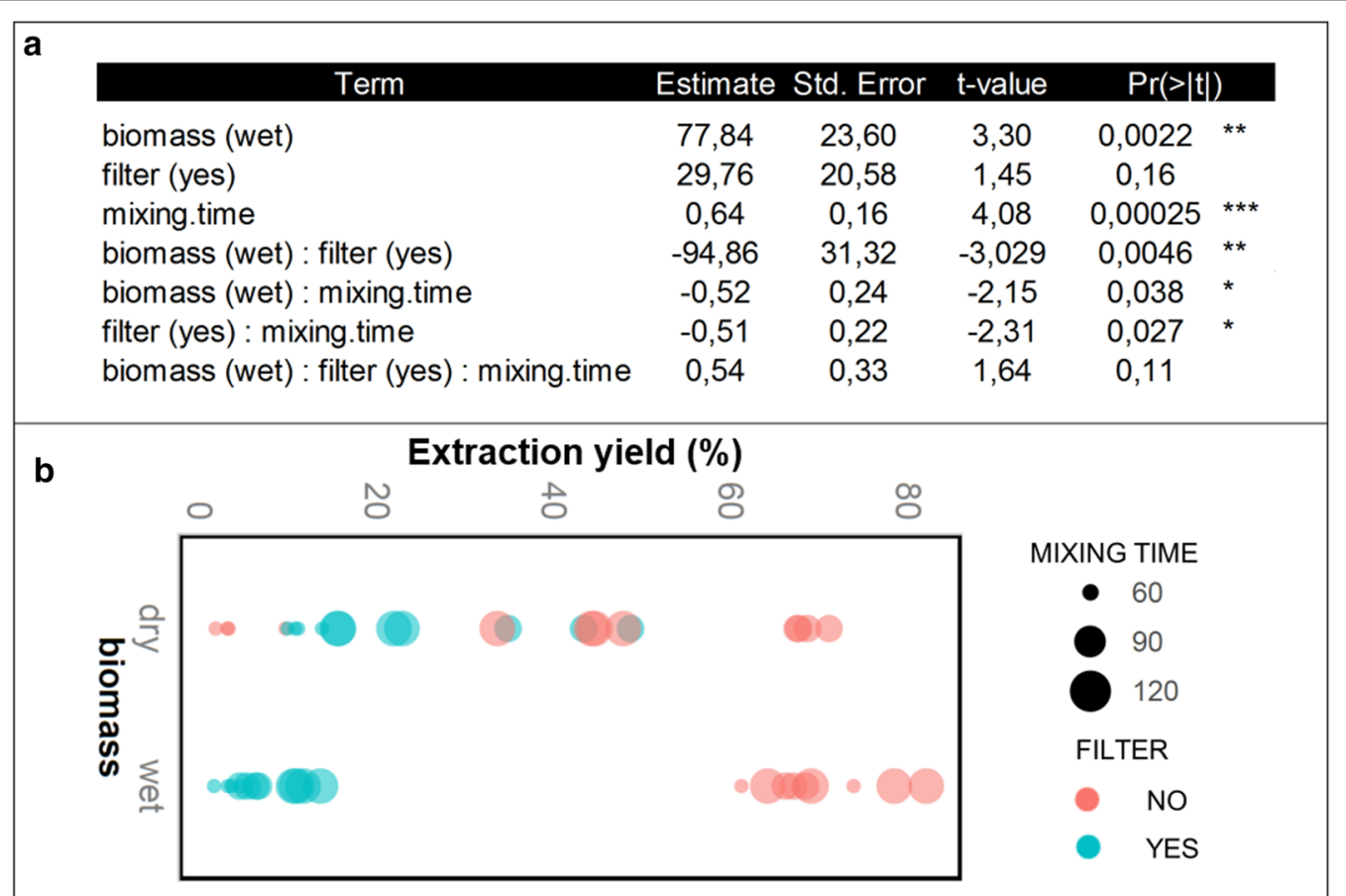

Fig. 3 Combined effect of experimental factors. a Regression analysis for modelling the relationships between the response variable (extraction yield) and the explanatory variables (paper filter, mixing time and pellet) was conducted by fitting a regression model through the Generalized Additive Models for Location, Scale and Shape (GAMLSS) package in the R statistical computing environment. The distribution for the response variable in the GAMLSS was selected from the normal family of distributions. The table shows the partial regression coefficients and standard errors of a regression model inclusive of interaction terms, the associated $t$-statistics and $P$-values. $\mathbf{b}$ Shown is the decreased extraction yield associated with the usage of wet pellet and the presence of the paper filter by mixing time

displayed in Fig. 3b. Indeed, combining filter with wet pellet corresponds to the cluster associated with the lowest yield, whereas the usage of wet pellet and the removal of the paper filter correspond to the cluster associated with the highest extraction yield. This observation can reflect the fact that the barrier action exerted by the filter is augmented when the biomass is wet, likely owing to the hydrophilic properties of the filter, which becomes a sponge in contact with water. When the biomass is dry, the filter pores may be more available to the solvent transit. Moreover, in the presence of filter, stirring was not possible, so that the only energy allowing the interaction between solvent and biomass was generated by keeping the temperature close to the solvent boiling point.

\section{PHB characterization \\ Differential scanning calorimetry (DSC) and thermal gravimetric analysis (TGA)}

The thermal properties of the purified PHB are reported in Table 2 and illustrated in Additional file 2: Figure S1. The degradation temperature $\left(T_{\mathrm{d}}\right)$, which was found to be around $300{ }^{\circ} \mathrm{C}$, is thus comparable between samples extracted by chloroform and by DMC. In contrast, the glass transition temperature $\left(T_{\mathrm{g}}\right)$ tends to increase, in particular as a consequence of using wet biomass. The melting temperature $\left(T_{\mathrm{m}}\right)$ of the control sample is about 4 and $6{ }^{\circ} \mathrm{C}$ below that of the samples obtained by DMC-based extractions. A good agreement with values reported in the literature is found [14, 15, 24]. Pronounced differences were found in the melting enthalpy $\left(\Delta H_{\mathrm{m}}\right)$ and crystallinity (degree of crystallinity) when comparing the solvents used. Interestingly, the differences were found to depend also on the biomass state. It is known that the physical properties of a biopolymer rely on the polymer molecular weight, which in turn depends on the applied extraction procedures [14, 24, 33]. More precisely, in vivo PHB chains are stabilized by a significant concentration of water content, around $10-15 \%$, which forms hydrogen bonds with the carbonyl groups of the biopolymer, forming a pseudo-crosslink [23, 34]. However, pre-treatment steps such as lyophilization or air-drying, expose the polymer to excessive energy, causing a decrease of water content. The consequences are the rearrangement of $\mathrm{PHB}$ chains and a change in polymer crystallinity [23]. Therefore, the enthalpy of crystallization $\left(\Delta H_{\mathrm{c}}\right)$, which reflects the energy applied per gramme 


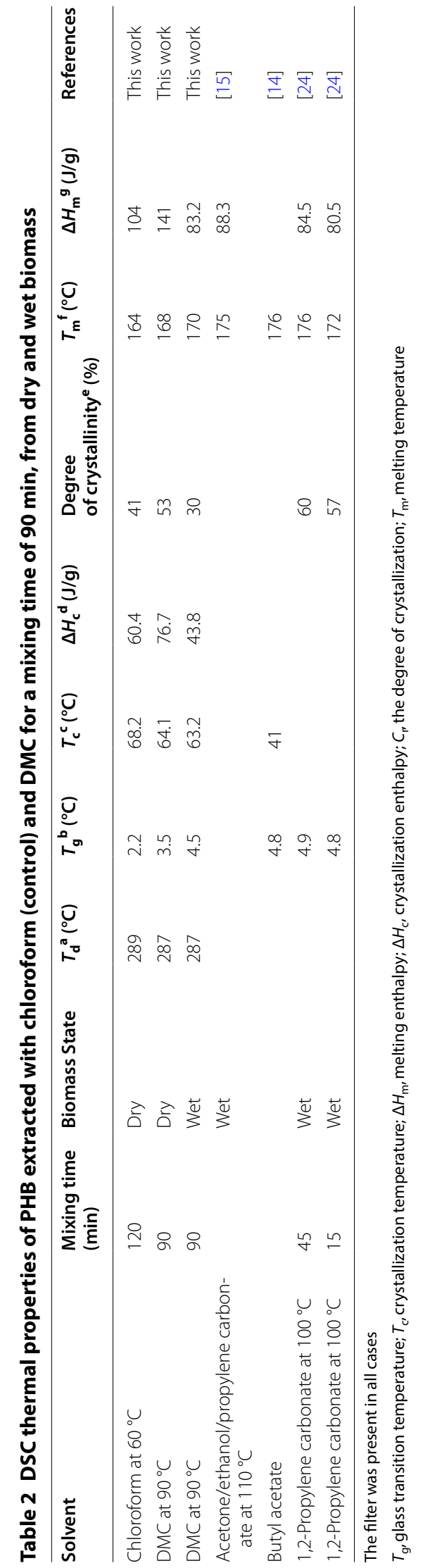


of produced crystal, varies in the same way. As a result, the extraction efficiency is affected too [31]. In conclusion, the higher extraction efficiency observed in wet biomass could depend on a better interaction between the solvent and the PHB branches.

\section{Attenuated total reflectance infrared (ATR)}

The IR spectrum of a sample represents its total chemical composition where every chemical compound in the sample makes its own distinct contribution to the absorbance spectrum. The total spectrum is determined by the chemical structure of each component and the degree to which each component contributes, directly related to the concentrations of the components of the sample. Thus, it is possible to have an idea of impurities present in the samples. The main impurities for PHB are cellular proteins, lipids, fatty acids in the ester form and phosphodiester from backbone of nucleic acids (DNA and RNA) or phosphorylated proteins/polyphosphate storage products [35, 36]. A second type of impurities is determined by the chemical compounds used for the purification themselves. The main adsorption bands of PHB are presented in Fig. 4.

The band at $1,720 \mathrm{~cm}^{-1}$ corresponds to the ester carbonyl group stretching $\left(v_{\mathrm{CO}}\right)$ typical of PHB, lipids and fatty acids while the overtone at $3436 \mathrm{~cm}^{-1}$ it is characteristic of PHB and other PHA [37, 38]. The band at $1452 \mathrm{~cm}^{-1}$ is related to the asymmetric bending of $-\mathrm{CH}_{2}$ or $-\mathrm{CH}_{3}\left(\delta_{\mathrm{CH} 2} ; \delta_{\mathrm{CH} 3}\right)$ present in PHB and proteins [39]. The bends at 2969 and $2927 \mathrm{~cm}^{-1}$ indicate the presence of an alkyl $-\mathrm{CH}_{3}$ group.

It is possible to evidence the main impurities from their characteristic bands, e.g. the presence of proteins can be evidenced by the Amide I and Amide II bands at, respectively, about $1650 \mathrm{~cm}^{-1}$ and $1540 \mathrm{~cm}^{-1}$. DNA, RNA and another polyphosphate can be evidenced from the symmetric stretching $\mathrm{P}=\mathrm{O}\left(v_{\mathrm{PO}}\right)$ at $1080 \mathrm{~cm}^{-1}$ [40]. Spectra

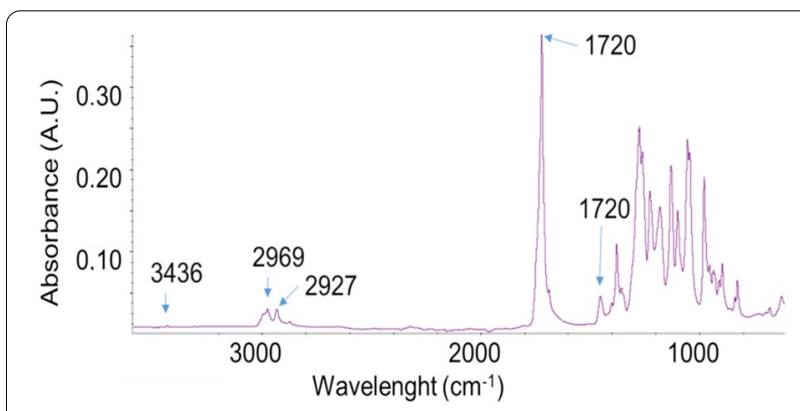

Fig. 4 ATR infrared analysis of PHB sample extracted by dry biomass with DMC/ethanol for $120 \mathrm{~min} .1720 \mathrm{~cm}^{-1} v_{\mathrm{CO}} ; 3436 \mathrm{~cm}^{-1} v_{\mathrm{CO}}$ overtone; $1452 \mathrm{~cm}^{-1} \delta \mathrm{a}_{\mathrm{CH} 2} ; \delta \mathrm{a}_{\mathrm{CH} 3} 2969$ and $2927 \mathrm{~cm}^{-1} \mathrm{v}_{\mathrm{CH} 3}$ of the other representative samples are reported in the Additional file 2: Figure S2.

\section{Molecular weight}

The molecular weights (MW) of PHB extracted by using DMC and chloroform are reported in Table 3 and compared on the basis of equal mixing time.

The outcome of viscosimeter analysis strictly depends on the constant value used in the Mark-Houwink equation (Eq. 3), which has been selected in line with the experimental conditions applied in this study. The molecular weights of PHB presented herein, are consistent with literature data: MW of PHB ranges between 0.5 and $20 \times 10^{6} \mathrm{Da}$ when feeding recombinant $E$. coli with glucose [41-43]. Besides that, PHB extracted from wet biomass using DMC is about $1 \mathrm{MDa}$, while lower values, i.e. 0.23 and $0.35 \mathrm{MDa}$, are recorded for dry biomass extracted with DMC and chloroform, respectively. It may appear that the absence of water favours a molecular degradation of the polymer chains, which could consequently affect the extraction yield. Although a clear explanation to this regard is not yet demonstrated, similar data were described for lyophilized cells of Cupriavidus necator exposed to $100^{\circ}$ and $120^{\circ} \mathrm{C}$ in cyclohexanone [44].

\section{LCA analysis}

Prior studies have noted the importance of the LCA application in biopolymers production [45, 46]. Therefore, this study assessed the potential lifecycle environmental impacts of PHB extraction based on DMC compared with chloroform. As it has been explained in the LCI section, two PHB production scenarios were assessed: one based on chloroform/hexane and the other on DMC/ethanol. In line with Righi et al. [47], our analysis revealed dry pellet without the application of filter to be the best solutions in terms of LCA and for this reason the relative LCA results listed for each ILCD impact categories are shown in Table 4.

To accurately represent impacts with different units in the same graphic, Fig. 5 provides the environmental impacts in relative percentage.

Table 3 Average values of the MW of the extracted PHB at the different experimental conditions

\begin{tabular}{llll}
\hline Extraction & $\begin{array}{l}\text { Mixing time } \\
(\mathbf{m i n})\end{array}$ & Biomass & PHB MW (MDa) \\
\hline Chloroform/hexane & 120 & Dry & 0.35 \\
DMC/ethanol & 120 & Dry & 0.23 \\
DMC/ethanol & 120 & Wet & 1.1 \\
\hline
\end{tabular}


Table 4 Comparative characterization LCA results per $1 \mathrm{~g}$ of PHB produced from DMC/ethanol (dry biomass) or from chloroform/hexane

\begin{tabular}{|c|c|c|c|c|}
\hline Impact category & Abbreviation & Unit & $\begin{array}{l}\text { PHB from DMC/ } \\
\text { ethanol }\end{array}$ & $\begin{array}{l}\text { PHB } \\
\text { from chloroform/ } \\
\text { hexane }\end{array}$ \\
\hline Climate change & CC & $\mathrm{kg} \mathrm{CO}{ }_{2 \text { eq }}$ & $5.34 \cdot 10^{2}$ & $2.09 \cdot 10^{2}$ \\
\hline Ozone depletion & OD & $\mathrm{kg} \mathrm{CFC-11} \mathrm{eq}$ & $1.37 \cdot 10^{-5}$ & $3.65 \cdot 10^{-2}$ \\
\hline Human toxicity, non-cancer effects & HTNC & CTUh & $1.84 \cdot 10^{-5}$ & $2.49 \cdot 10^{-5}$ \\
\hline Human toxicity, cancer effects & HTC & CTUh & $2.45 \cdot 10^{-6}$ & $3.47 \cdot 10^{-6}$ \\
\hline Particulate matter & PM & $\mathrm{kg} \mathrm{PM}_{2.5 \mathrm{eq}}$ & $1.81 \cdot 10^{-1}$ & $9.07 \cdot 10^{-2}$ \\
\hline Ionizing radiation in human health & $\mathrm{IRHH}$ & $\mathrm{kBq} \mathrm{U}^{235}$ eq & $8.29 \cdot 10^{\circ}$ & $1.09 \cdot 10^{1}$ \\
\hline Ionizing radiation in ecosystems & IRE & CTUe & $6.40 \cdot 10^{-5}$ & $7.90 \cdot 10^{-5}$ \\
\hline Photochemical ozone formation & POF & $\mathrm{kg} \mathrm{NMVOC}$ eq & $1.66 \cdot 10^{0}$ & $5.14 \cdot 10^{-1}$ \\
\hline Acidification & $A C$ & $\mathrm{molc} \mathrm{H}_{\text {eq }}$ & $2.47 \cdot 10^{0}$ & $8.87 \cdot 10^{-1}$ \\
\hline Terrestrial eutrophication & TE & molc $N_{\text {eq }}$ & $4.23 \cdot 10^{0}$ & $1.26 \cdot 10^{0}$ \\
\hline Freshwater eutrophication & FWE & $\mathrm{kg} \mathrm{P}_{\text {eq }}$ & $8.80 \cdot 10^{-2}$ & $8.72 \cdot 10^{-3}$ \\
\hline Marine eutrophication & ME & $\mathrm{kg} \mathrm{N}$ eq & $2.67 \cdot 10^{-1}$ & $1.15 \cdot 10^{-1}$ \\
\hline Freshwater ecotoxicity & WT & CTUe & $2.13 \cdot 10^{2}$ & $5.63 \cdot 10^{1}$ \\
\hline Land use & $L U$ & $\mathrm{~kg} C_{\text {deficit }}$ & $1.36 \cdot 10^{2}$ & $1.40 \cdot 10^{2}$ \\
\hline Water resource depletion & WRD & $\mathrm{m}^{3} \mathrm{H}_{2} \mathrm{O}_{\text {eq }}$ & $1.49 \cdot 10^{2}$ & $1.85 \cdot 10^{2}$ \\
\hline $\begin{array}{l}\text { Mineral, fossil and renewable resource deple- } \\
\text { tion }\end{array}$ & FFD & $\mathrm{kg} \mathrm{Sb}$ eq & $1.11 \cdot 10^{-2}$ & $7.73 \cdot 10^{-3}$ \\
\hline
\end{tabular}

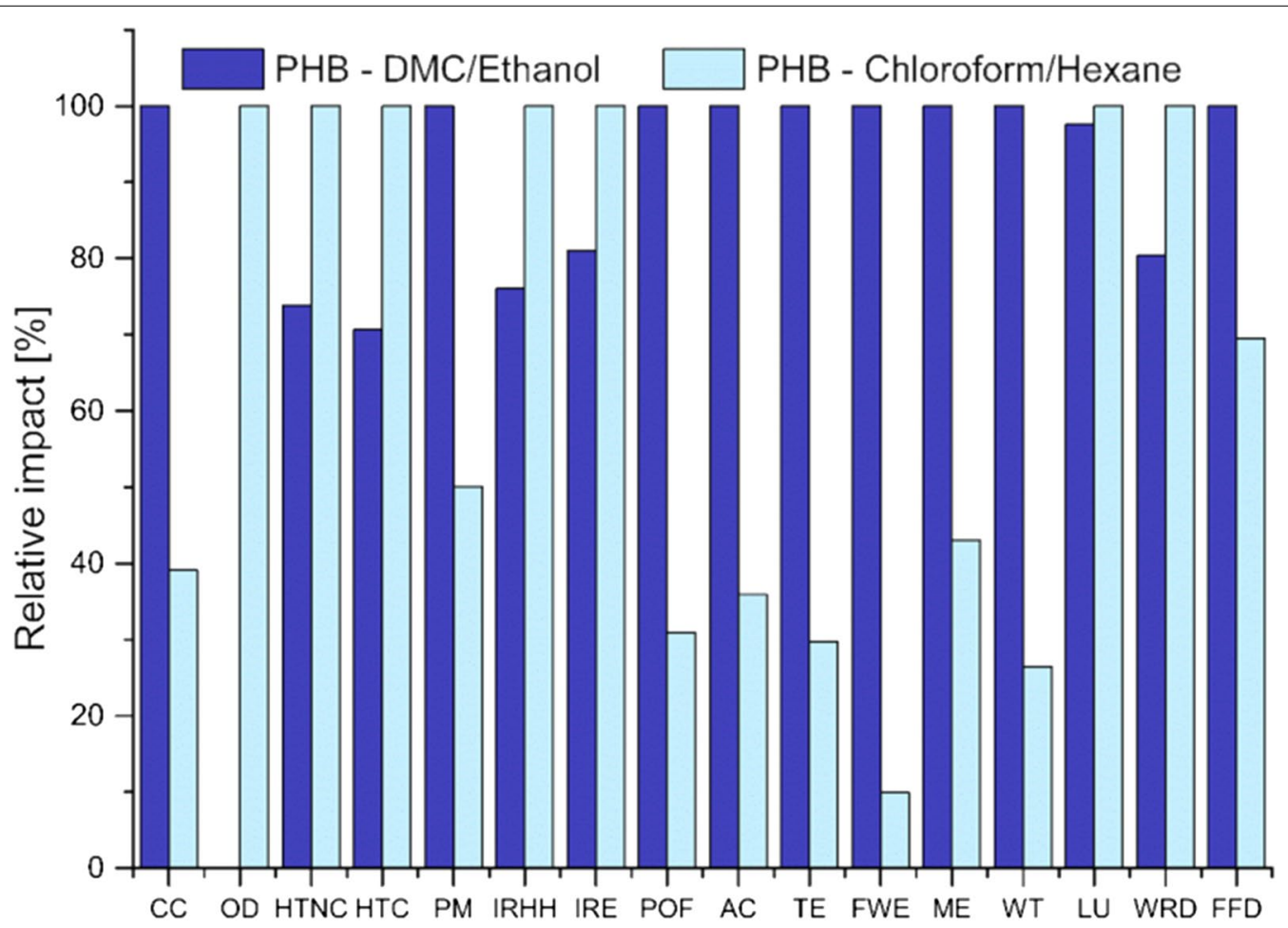

Fig. 5 Comparative LCA results of PHB production for the two assessed routes. DMC/ethanol or chloroform/hexane as solvent/antisolvent 
The comparative results for $1 \mathrm{~g}$ of $\mathrm{PHB}$ produced through two different techniques showed that PHB extraction from DMC/ethanol got better environmental results in OD, HTNC, HTC, IRHH, IR, LU and WRD. The remaining impact categories assessed revealed better environmental behaviour for the PHB extraction based on chloroform/hexane. In order to determine the main contributing phases for each impact category, a contribution analysis was included. Figure 6 shows the environmental contributions of the items in the PHB extraction process in both assessed systems.

The lowest influence of energy is represented by the chloroform/hexane case study (Fig. 6) since a minor amount of solvent is used to get a similar amount of PHB and since the enthalpy of chloroform vaporization is lower than that of DMC. Globally, the chloroform in the chloroform/hexane extraction route has higher influence on the environmental profile than DMC. In fact, the case of DMC/ethanol extraction the environmental contribution is almost equally distributed between the two chemicals. This fact means that acting on chloroform will lower the environmental impact of the system easily. However, in order to reduce the environmental impacts generated by the DMC/ethanol extraction, both compounds have to be adjusted. Ozone depletion (OD) represents the destructive effects on the stratospheric ozone layer over a time horizon of 100 years. The contribution of DMC/ ethanol case study to this category is halved compared to that of chloroform/hexane extraction route. Comparative toxic unit for humans (CTUh) is an indicator which estimates the increase in morbidity in the total human population per unit of mass of emitted chemical [48]. Human toxicity, cancer and non-cancer effects, ionizing radiation on human health (IRHH) and ecosystems (IRE) got better results in DMC/ethanol case study compared to the chloroform/hexane one. As shown in Fig. 6a, this is because of the significant contribution of chloroform to this category. The same tendency was observed for land use (LU) and water resource depletion (WRD) indicators. One of the most known environmental categories is climate change $(\mathrm{CC})$ which represents global warming potential in $\mathrm{kg}$ of $\mathrm{CO}_{2}$-equivalents. This indicator favoured the chloroform/hexane extraction rather than the DMC/ethanol application. It is a general opinion that DMC represents a promising substitute to conventional chlorinated solvents because of their lower human toxicity. However, a deeper analysis highlights the drawbacks of using DMC in other environmental categories, such as fossil fuel depletion (FFD), water toxicity eutrophication (WTE), acidification (AC) (10 of 16 environmental categories).
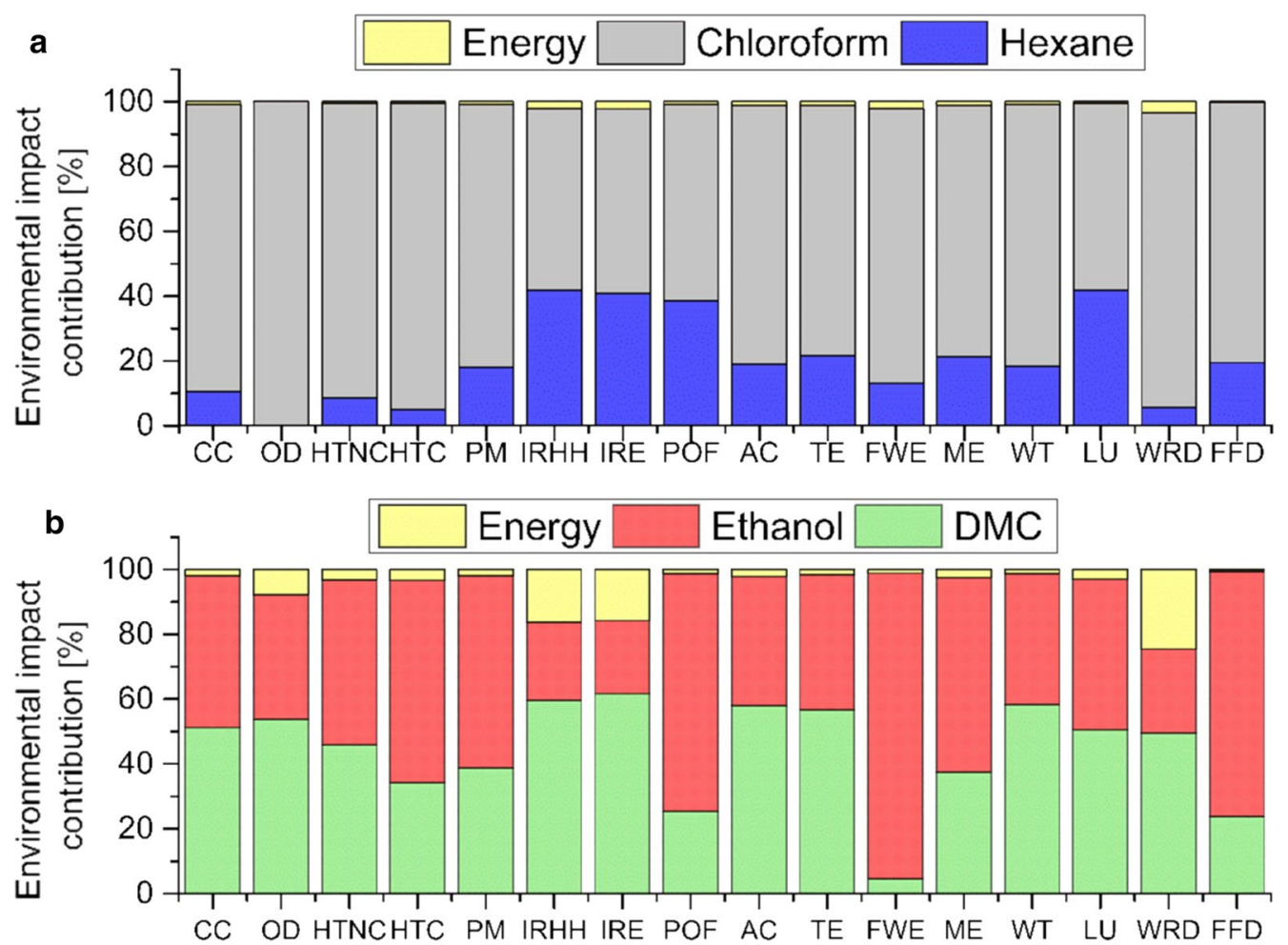

Fig. 6 Environmental contributions (\%) of $1 \mathrm{~g}$ of PHB. a PHB produced with chloroform and hexane. $\mathbf{b}$ PHB produced with DMC and ethanol as solvent and antisolvent 
Notable is also the level of affection associated to the use of ethanol on other relevant categories (FEW, POF and FFD). Hence, replacing ethanol with other less impacting compounds would change the impact on these or more categories in support of the DMC/ethanol extraction route (Figs. 5 and 6b). LCA analysis related to biopolymers shows a large variation among environmental results. The fossil polymer with the lowest overall life cycle impacts is polypropylene. Published works agree that PHAs, including PHB performed better in CC and FFD categories compared with conventional fossil-based polymers [46]. This is because the studies that reported lower CC impact values accounted for carbon uptake during biomass growth or using waste stream [49]. Nevertheless, to our knowledge, there are no studies in literature that consider the same boundary conditions. Hence, it is difficult to give balanced reading of our results. In summary, his examination gave rise to divergent issues which should be considered for further process optimization and unbiased analysis of the results.

\section{Conclusions}

The multifaceted exploration of DMC-based PHB extraction herein reported extends the knowledge of the variables affecting PHB recovery. Among these variables, mixing time significantly influenced the extraction yield of PHB. Physical and molecular properties changed depending on the biomass state and solvent/antisolvent choice. Wet biomass generates PHB with low crystallinity grade and high molecular weight. Despite the wellknown potential of chloroform/hexane-based extraction, only slight differences in PHB extraction yields were observed when compared to DMC/ethanol application. According to our LCA analysis, DMC could be a promising substitute to chloroform. Indicators like human toxicity and ionizing radiation, ozone depletion and water resources depletion show optimal values when DMC/ ethanol is applied. Nevertheless, other relevant environmental categories have a minor impact when using chloroform/hexane extraction compared to DMC/ethanol one. In disagreement with similar studies, the findings of the present work do not completely support the application of DMC as a green solvent. However, the choice of the antisolvent can modify the level of impact on the examined categories. Despite the relatively limited labscale investigation, this work offers novel and valuable insights into PHB extraction process, including environmental aspects not discussed so far.

\section{Methods}

\section{Biomass cultivation}

The bacterial strain used in this study was kindly supplied by the group of Dr. Auxiliadora M. Prieto (CSIC, Spain).
It is a genetically modified E. coli BL21 (DE3), hosting a plasmid with the three genes devoted to the PHB biosynthetic (phb $A B C$ ) coming from Ralstonia eutropha H16 and a chloramphenicol resistance, which are activated on glucose [50]. Prior to begin the experimental campaign, the biomass production by the engineered E. coli was evaluated. For each flask filled with $250 \mathrm{~mL}$ of working volume and supplemented with $10 \mathrm{gL}^{-1}$ of glucose, about $2.3 \mathrm{~g}$ of biomass containing $54 \%$ of PHB were ensured after $12 \mathrm{~h}$ of growth approximately. Hence, the described cultivation technique was applied to the whole experimental trial. The strain, stocked at $-20{ }^{\circ} \mathrm{C}$ in $15 \% \mathrm{v} / \mathrm{v}$ glycerol, was cultured in Luria-Bertani (LB) medium supplemented with chloramphenicol $(20 \mu \mathrm{g} /$ $\mathrm{mL})$ and glucose $(10 \% \mathrm{v} / \mathrm{v})$. Each culture was prepared in Erlenmeyer flasks filled with around $40 \%$ of culture broth. To maximize the biomass growth, pre-cultures of $70 \mathrm{~mL}$ and culture of $250 \mathrm{~mL}$ flask were prepared, respectively. A volume of $1.5 \mathrm{~mL}$ of $E$. coli glycerol stock was transferred to the preculture flask and incubated for $12 \mathrm{~h}$, at $37{ }^{\circ} \mathrm{C}$ and $200 \mathrm{rpm}$ (ES-20/60, Orbital ShakerIncubator, Biosan) [51]. After it, a pre-culture volume was transferred to fresh LB medium to have an initial optical density at $600 \mathrm{~nm}\left(\mathrm{OD}_{600}\right)$ of 0.3 , in a culture volume of $250 \mathrm{~mL}$. A volume of $250 \mathrm{~mL}$ containing biomass were distributed in $50 \mathrm{~mL}$ falcon tubes and centrifuged two times at $4696 \times g$ for $15 \mathrm{~min}$, to collect the cell pellet (SL 16R Centrifuge, Thermo Fischer Scientific, Germany). The obtained pellet was washed with deionized $\mathrm{H}_{2} \mathrm{O}$ and centrifuged at $4696 \times g$ for $15 \mathrm{~min}$. Depending on the selected extraction process, the wet cell pellet was directly treated or dried in the oven at $105^{\circ} \mathrm{C}$ for $12 \mathrm{~h}$ and ground by a ceramic mortar and pestle.

\section{Chloroform/hexane-based extraction}

As the reference method [15], the PHB was extracted by treating dry biomass with $99 \%$ chloroform/ $95 \%$ hexane, as a solvent/antisolvent couple, respectively. The solvent was added to the dry pellet in a volumetric ratio of $15: 1$, stirred at $60{ }^{\circ} \mathrm{C}$ for $120 \mathrm{~min}$. In the case of filter-mediated extraction, wet or dry biomass was previously wrapped in a paper filter with a pore size of $11 \mu \mathrm{m}$, arranged as a teabag container (Whatman grade 1). At the end of the reaction the entire solution was centrifuged at $4696 \times g$ for 5 to $10 \mathrm{~min}$ to remove the pellet. When the filter was present, the centrifugation step was not necessary. PHB precipitation was obtained by the addition of hexane, used as antisolvent because of its miscibility with the solvent. The combination of the two causes a change of solvent mixture properties which reduces the bio-polymer solubility and generates supersaturation followed by a rapid crystallization $[15,52,53]$. 
95\% hexane was added to chloroform in a volumetric ratio of $1: 3$. Hence, the solvent:antisolvent mixture was left at $4{ }^{\circ} \mathrm{C}$ for $24 \mathrm{~h}$, after which the precipitated PHB was separated from hexane with vacuum filtration and finally air-dried.

\section{Dimethyl carbonate/ethanol-based extraction}

The PHB extraction with 99\% DMC and ethanol is based on a modified protocol by Samorì et al., [32] consisting of different reaction mixing time, pellet texture and filter use (Fig. 7).

In case of direct solvent-biomass extraction, the wet or dry pellet was put directly in 20-mL glass bottles, where DMC was added to the collected biomass respecting the ratio $2.5 \%(\mathrm{w} / \mathrm{v})$. The reaction was set under continuous stirring at $90{ }^{\circ} \mathrm{C}$, for to $60,90,120$ min depending on the experimental run. At the end of each extraction, the solution was transferred into 50 -mL falcon and centrifuged at $4696 \times g$ for $10 \mathrm{~min}$, to separate the organic phase hosting the PHB from the biomass. Therefore, the organic phase was recovered, and pure ethanol was added at a DMC:ethanol volumetric ratio of $1: 3$ to enable PHB precipitation. The mixture was stored for $12 \mathrm{~h}$ at $4{ }^{\circ} \mathrm{C}$. The PHB was then filtered via vacuum pump and air-dried. In the case of filter-mediated extraction, wet or dry biomass was in a paper filter arranged as a tea-bag container (Whatman grade 1). Hence, there was no need to centrifuge the samples to separate the PHB-rich organic phase from the exhaust biomass, but just $\mathrm{PHB}$ precipitation was required via ethanol supplement.

\section{PHB quantification}

To verify the specific amount of PHB produced by genetically modified $E$. coli cells during each test, every time a new culture was set up a sample corresponding to $5 \mathrm{~mL}$ of final culture broth was kept and stored at $-20{ }^{\circ} \mathrm{C}$ for successive analysis of the cell dry weight and of the correspondent PHB amount. Cell dry weight was obtained gravimetrically. The sample collected was centrifuged at $18,816 \times g$ for $5 \mathrm{~min}$, washed two times and dried at $80{ }^{\circ} \mathrm{C}$ for $12 \mathrm{~h}$ in an oven. Once estimated the correspondent biomass concentration $\left(\mathrm{g} \mathrm{L}^{-1}\right), 5 \mathrm{mg}$ of biomass were hydrolysed by $1 \mathrm{~mL}$ of $96 \% \mathrm{H}_{2} \mathrm{SO}_{4}$ under stirring of $800 \mathrm{rpm}$, into an agitated oil bath at $90{ }^{\circ} \mathrm{C}$ for one hour. At the end of the reaction, a dilution of 1:1000 was done, and the samples were analysed by HPLC equipped with a column ROA-organic acid $\mathrm{H}+$ (8\%) (Phenomenex) and a photodiode array detectors (PDA) under an isocratic flux of $0.7 \mathrm{~mL} \mathrm{~min}{ }^{-1}$ of $5 \mathrm{mM}$ of $\mathrm{H}_{2} \mathrm{SO}_{4}$ and a temperature of $50{ }^{\circ} \mathrm{C}$. The PHB-related peak was revealed at $210 \mathrm{~nm}$ with an elution time of 23.09 min, which corresponds to the crotonic acid (the monomer coming from the PHB hydrolysation) used as a reference standard [54]. The PHB yield was estimated on the base of Eq. 1:

$$
\begin{aligned}
& \text { PHB extraction yield }(\%) \\
& \quad=\frac{\text { purified } \operatorname{PHB}(\mathrm{g})}{\text { PHB present in the treated biomass }(\mathrm{g})} .
\end{aligned}
$$

\section{PHB purity estimation}

The purity of the recovered PHB was investigated by the HPLC method above described. Representative samples of the extracted PHB were ground into a ceramic mortar, hydrolysed by $\mathrm{H}_{2} \mathrm{SO}_{4}$ (ground and hydrolysed biomass) and quantified as follows (Eq. 2):

$$
\text { PHB purity }(\%)=\frac{\text { HPLC quantified of extracted } \mathrm{PHB}(\mathrm{g})}{\text { ground and hydrolysed } \mathrm{PHB}(\mathrm{g})} \text {. }
$$

1

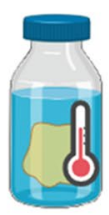

Extraction with solvent $\left(\mathrm{CHCl}_{3}\right.$ or DMC) at controlled temperature and mixing time
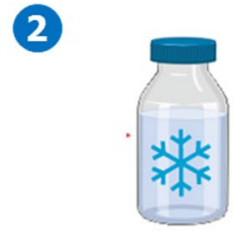

3

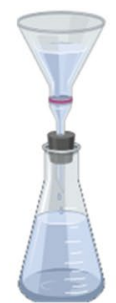

Recovery of PHBcontaining phase and addition of hexane or ethanol, $\mathrm{O} / \mathrm{N}$ at $4^{\circ} \mathrm{C}$

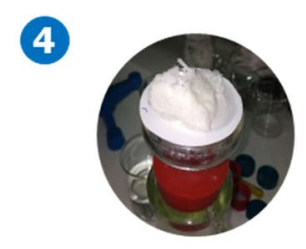

Vacuum pump filtration
Filter drying

Fig. 7 Extraction phases: (1) the solvent reacts for a certain time with the biomass which is in the form of a pellet, (2) an antisolvent is added to precipitate the PHB and left overnight at $4^{\circ} \mathrm{C}$, (3) the solution is filtered via vacuum, (4) the PHB is dried on paper filter. Created with http://www. Biorender.com 


\section{Experimental design of the extraction process}

To explore the potential of using DMC-based extraction, rather than chloroform, the following design of experiments (DoE) was conceived. Three experimental variables, namely mixing time, pellet and the presence of filter were accounted for (Table 5). The mixing time experimental variable could assume three discrete levels (60, 90, $120 \mathrm{~min}$ ), while the categorical pellet and filter data types assumed binary values, dry/wet and yes/no, respectively.

\section{Data analysis}

Regression analysis for modelling the relationships between the response variable (extraction yield) and the explanatory variables (mixing time, pellet and filter) was conducted by fitting a regression model inclusive of the interaction terms through the Generalized Additive Models for Location, Scale and Shape (GAMLSS) package in the $\mathrm{R}$ statistical computing environment [55, 56]. The distribution for the response variable in the GAMLSS was selected from the normal family of distributions. Significance of the regression coefficients resulting from model fitting was evaluated by comparing the ratio of coefficients estimates and their standard errors with a t distribution $(\alpha=0.01)$.

\section{Differential scanning calorimetry (DSC) and thermogravimetric analysis (TGA)}

DSC was applied to study the thermal transition properties of the PHB extracted by the standard chlorinated solvent compared to the DMC-based extraction (DSC 204 F1 Phoenix ${ }^{\circledR}$ Netzsch). The analysis was led on both wet and dry biomass extracted for 90 min which is the mixing time reporting the highest PHB yield. The decomposition temperatures of the extracted polymer were determined

\section{Table 5 Text matrix for the DoE}

\begin{tabular}{llll}
\hline Run & Mixing time $(\boldsymbol{m i n})$ & Pellet & Filter \\
\hline 1 & 90 & Dry & No \\
2 & 120 & Dry & No \\
3 & 60 & Dry & Yes \\
4 & 60 & Dry & No \\
5 & 90 & Dry & Yes \\
6 & 120 & Dry & Yes \\
7 & 90 & Wet & Yes \\
8 & 60 & Wet & Yes \\
9 & 120 & Wet & Yes \\
10 & 90 & Wet & No \\
11 & 120 & Wet & No \\
12 & 60 & Wet & No \\
\hline
\end{tabular}

by TGA, at $10{ }^{\circ} \mathrm{C} / \mathrm{min}$ (Mettler Toledo TGA/SDTA $851 \mathrm{e}$ system). The studies were performed under an Argon flux of $50 \mathrm{~mL} \mathrm{~min}{ }^{-1}$, scanning a temperature range going from 25 to $500{ }^{\circ} \mathrm{C}$.

\section{Attenuated total reflection (ATR)}

Fourier transform infrared (FTIR) spectroscopy (Bruker Tensor II) was performed on the materials in attenuated total reflection (ATR) configuration. The spectra were acquired accumulating 32 scans in $4000-600 \mathrm{~cm}^{-1}$ range with resolution of $2 \mathrm{~cm}^{-1}$.

\section{Determination of PHB molecular weight}

The average molecular weight determined through a viscosimeter analysis $[11,57]$ made by a Cannon-Fenske tube $\left(100 \mathrm{~mL}\right.$ size) at a temperature of $29.3{ }^{\circ} \mathrm{C}$ (Fungi$\mathrm{Lab})$. Before performing the quantification, purified polymers were dissolved in pure chloroform at $50{ }^{\circ} \mathrm{C}$ under gentle stirring in a closed vial, for being filtered through a qualitative filter paper for technical use (Whatman grade 1575) and cast on a $50 \mathrm{~mL}$ Becker. Hence, the obtained PHB dry films were dissolved in chloroform at $30{ }^{\circ} \mathrm{C}$ in a closed vial at a concentration of $0.5 \% \mathrm{w} / \mathrm{w}$ and poured in the viscometer, which was located in a thermostat and incubated $10 \mathrm{~min}$ before to perform the analysis. The PHB solution flow time was measured, and successive measurements were made on PHB serial dilutions. The molecular weight of standard PHB (Goodfellow) used as reference was $5.7 \mathrm{E}+05 \mathrm{~g} \mathrm{~mol}^{-1}$. Intrinsic viscosity $(\eta)$ and relative final molecular weights were extrapolated by Mark-Houwink relationship (Eq. 3), using the following experimental formula reported [57]:

$$
\eta=1.18 \times 10^{-4} M_{\mathrm{w}}^{0.78} .
$$

From each measurement the relative $\left(\eta_{\mathrm{r}}\right)$, specific $\left(\eta_{\mathrm{sp}}\right)$ and reduced viscosity $\left(\eta_{\text {red }}\right)$ were calculated, following the reported equations, where the concentration $(C)$ and $\eta_{\text {red }}$ are expressed in $\mathrm{g} \mathrm{mL}^{-1}$ and $\mathrm{mL} \mathrm{g}^{-1}$, respectively:

$$
\begin{aligned}
& \eta_{\mathrm{r}}=\frac{\eta_{\text {sol }}}{\eta_{\text {solv }}} \\
& \eta_{\text {sp }}=\frac{\eta_{\text {sol }}-\eta_{\text {solv }}}{\eta_{\text {solv }}}, \\
& \eta_{\text {red }}=\frac{\eta_{\text {sp }}}{C} .
\end{aligned}
$$

\section{Life cycle assessment method}

According to ISO 14040-44 $[58,59]$ an LCA includes four stages: (i) goal and scope definition, (ii) life cycle 
inventory, (iii) life cycle impact assessments and (iv) interpretation of the results.

(i) Goal and scope stage consists of the identification of the LCA purpose, defining the functional unit, the sources of data, the boundaries of the analysis and the additional tools used in the LCA. A cradleto-gate approach has been chosen for the LCA study. The goal was to analyse the influence of the solvent/antisolvent used in PHB extraction. Initial biomass amount, solvent, antisolvent and the enthalpy of vaporization were the items included in the assessment of PHB production. Therefore, the environmental results will be got per gramme of PHB production.

(ii) Life cycle inventory (LCI) consists of the quantification of the inputs and outputs associated with the functional unit. Typically, inventory data include raw materials and energy consumption, and the emission of solid, liquid, and gaseous wastes.

To quantify the environmental impacts of the extraction process, it was selected the standard extraction with chloroform and hexane and the PHB production with DMC and ethanol.

In this research work, the LCI gathers solvent, antisolvent, energy to evaporate the solvent (enthalpy) and PHB. DMC enthalpy $(0.194 \mathrm{kWh} / \mathrm{kg})$ was reported by Breil et al. [60] and chloroform enthalpy $(0.069 \mathrm{kWh} / \mathrm{kg})$ by Holbrook [61]. This energy to vaporize the solvent was supposed to be part of the system as a low-voltage power source. The energy needed to vaporize chloroform is lower than DMC. Regarding the database, Ecoinvent 3.4 was implemented in the internationally acknowledged SimaPro 8 software to build the LCA. It is not always possible to find every single chemical compound in the common LCA databases. Hence, missing items are often modelled according to stoichiometry or information reported in the literature. In the present work, DMC was modelled according to Righi et al. [62]. To be as replicable and transparent as possible, the dataset has been declared. Dataset names from Ecoinvent database used to conduct the comparative LCA are shown in Table 6.

(iii) Life cycle impact assessment (LCIA) consists in the quantification of the effects of the phases defined in the LCI. It foresees the selection of impact categories, firstly, and classification, secondly. It means that the elementary flows from the life cycle inventory were assigned to impact categories according to the ability of substances to contribute to different environmental problems. Subsequently, in the characterization stage, the impact of each emission or resource consumption is modelled quantitatively, according to the environmental assessment approach. The result is an impact score in a common unit to all contributions within the impact category by applying the so-called characterization factors (e.g. $\mathrm{kg} \mathrm{CO}$-equivalents for greenhouse gases contributing to the impact category Climate Change). For this purpose, there are several methods. The selection of impact categories is performed in line with the goal and scope definition of the LCA assessment [63]. The present study follows the International Reference Life Cycle Data System (ILCD) handbook methodology, developed by the European Joint Research Centre (JRC) [64]. This implementation corresponds to the ILCD version 1.0.9 of May 2016 [65]. This LCIA method includes 16 midpoint impact categories: Climate Change (CC), Ozone Depletion (OD), Human Toxicity, Non-Cancer effects (HTNC), Human Toxicity, Cancer effects (HTC), Particulate Matter (PM), Ionizing Radiation $\mathrm{HH}$ (human health) (IRHH), Ionizing Radiation E (ecosystems) (IRE), Photochemical Ozone Formation: (POF), Acidification (AC), Terrestrial Eutrophication (TE), Freshwater Eutrophication (FEW), Marine Eutrophication

Table 6 Life cycle inventory of PHB extraction process based on experimental results

\begin{tabular}{|c|c|c|c|c|c|c|}
\hline & \multicolumn{3}{|l|}{ PHB from DMC/ethanol (run 11) } & \multicolumn{3}{|c|}{ PHB from chloroform/hexane (standard extraction) } \\
\hline & Dataset & Amount & Unit & Dataset & Amount & Unit \\
\hline Output & $\mathrm{PHB}$ & 0.235 & g & $\mathrm{PHB}$ & 0.239 & $g$ \\
\hline \multirow[t]{4}{*}{ Inputs } & Biomass & 0.546 & g & Biomass & 0.55 & $g$ \\
\hline & DMC (modelled) & 23.01 & g & Hexane $\{G L O\} \mid$ market for | Alloc Def, $U$ & 15.84 & g \\
\hline & $\begin{array}{l}\text { Ethanol, without water, in } 99.7 \% \text { solution state, from } \\
\text { ethylene }\{\text { RER\}| ethylene hydration | Alloc Def, } U\end{array}$ & 50.89 & g & Trichloromethane $\{\mathrm{GLO}\} \mid$ market for | Alloc Def, $\mathrm{U}$ & 11.92 & g \\
\hline & $\begin{array}{l}\text { Electricity, low voltage \{Europe without Switzer- } \\
\text { land\}| market group for | Alloc Def, } U\end{array}$ & $4.463 \cdot 10^{-03}$ & kWh & $\begin{array}{l}\text { Electricity, low voltage \{Europe without Switzer- } \\
\text { land\}| market group for | Alloc Def, } U\end{array}$ & $8.177 \cdot 10^{-04}$ & $\mathrm{kWh}$ \\
\hline
\end{tabular}

Dataset from Ecoinvent database are reported in the table 
(ME), Freshwater Ecotoxicity (WT), Land Use (LU), Water Resource Depletion (WRD), Mineral, fossil and renewable resource depletion (FFD)

(iv) The interpretation phase of an LCA is the last step in every LCA study. It consists in the interpretation of LCI and LCIA results with the purpose of extracting relevant observations for further developments of a single process or significant conclusions in the case different processes have been compared.

\section{Supplementary Information}

The online version contains supplementary material available at https://doi. org/10.1186/s13068-020-01849-y.

Additional file 1: Table S1. Raw values corresponding to each experimental run (total 12).

Additional file 2: Figure S1. DSC curves of PHB samples. A) Chloroform/ Hexane (dry biomass); B) DMC/Ethanol for 90 min (dry biomass); C) DMC/ Ethanol for 90 min (wet biomass). The filter was applied to all three extractions. Figure S2. ATR spectra of PHB samples (1-6). Sample 1: PHB extracted from dry biomass with Chloroform/Hexane for $120 \mathrm{~min}$. Sample 2 and 3: PHB extracted with DMC/Ethanol for 90 min from dry and wet biomass, respectively. No filter was applied in sample 1-3. Sample 4: PHB extracted from dry biomass with Chloroform/Hexane for 120 min. Sample 5 and 6: PHB extracted with DMC/Ethanol for 90 min from dry and wet biomass, respectively. Filter was used in sample 4, 5, 7. The presence of amide I and amide II bands in sample 1 and 2 evidence the presence of proteins. There is no evidence of impurities from ATR analyses in sample 3 and 4 . A band at about $798 \mathrm{~cm}^{-1}$ may indicate the presence of some DMC residual in sample 5 and 6.

\section{Abbreviations}

AC: Acidification; ATR: Attenuated total reflectance infrared; CC: Climate change; CTUh: Comparative toxic unit for humans; DMC: Dimethyl carbonate; DSC: Differential scanning calorimetry; FEW: Freshwater eutrophication; FFD: Mineral, fossil and renewable resource depletion; HTC: Human toxicity cancer effects; HTNC: Human toxicity non-cancer effects; ILCD: International Reference Life Cycle Data System; IRE: Ionization radiation ecosystems; IRHH: lonizing radiation on human health; JRC: European Joint Research Centre; LCA: Life Cycle Assessment; LCI: Life Cycle Inventory; LCIA: Life Cycle Impact Assessment; LU: Land use; ME: Marine eutrophication; MW: Molecular weight; OD: Ozone depletion; PHAs: Polyhydroxyalkanoates; PHB: Poly-3-hydroxybutyrate; PM: Particulate matter; POF: Photochemical ozone formation; $T_{c}$ : Crystallization temperature; TE: Terrestrial eutrophication; $T_{\mathrm{g}}$ : Glass transition temperature; TGA: Thermogravimetric analysis; $T_{\mathrm{m}}$ : Melting temperature; WRD: Water resource depletion; WT: Freshwater toxicity; $\Delta H_{c}$ : Crystallization enthalpy; $\Delta H_{m}$ : Melting enthalpy.

\section{Acknowledgements}

We would like to acknowledge Dr. Auxiliadora Prieto of Centro de Investigaciones Biologicals of the National Research Council (CSIC-CIB) and her group of Polymer Biotechnology, who gently provided the E. coli strain used in this work. This research has been funded by the Horizon 2020 EU Framework Programme: CELBICON project, Grant agreement number: 679050, and by the POR FESR 2014/2020 Programme, Asse I - Azione I.1b.2.2 Regione Piemonte, within the Piattaforma Tecnologica per la Bioeconomia in the frame of the PRIME project.

\section{Authors' contributions}

AAA, BM, SFG: conceived the study, designed, and perform the experiments, discussed, and elaborated the data, wrote the manuscript draft. EB: performed LCA analysis and contribute to write the manuscript draft. AR: curated the statistical analysis of the experimental data and contribute to write the manuscript draft. SB: contributed to the characterization of the PHB and support data interpretation. DF: supervised the work. All authors read and approved the final manuscript.

\section{Funding}

This work has been funded by the Horizon 2020 EU Framework Programme: CELBICON project, Grant agreement number: 679050. Open access funding provided by PRIME project funded by the POR FESR 2014/2020 Programme, Asse I - Azione I.1b.2.2 Regione Piemonte, within the Piattaforma Tecnologica per la Bioeconomia.

\section{Availability of data and materials}

All data generated or analysed during this study are included in this published article and its additional material files.

\section{Ethics approval and consent to participate}

Not applicable.

\section{Consent for publication}

Not applicable.

\section{Competing interests}

The authors declare that they have no competing interests.

\section{Author details}

${ }^{1}$ Department of Science and Applied Technology (DISAT), Polytechnic University of Turin, Corso Duca degli Abruzzi 24, 10129 Turin, Italy. ${ }^{2}$ Centre for Sustainable Future Technology (CSFT), Italian Institute of Technology, Via Livorno 60, 10144 Turin, Italy. ${ }^{3}$ Thermal and Fluid Engineering Department, Carlos III University of Madrid, Avenida de la Universidad 30, 28911 Leganés, Madrid, Spain.

Received: 21 September 2020 Accepted: 3 December 2020

Published online: 07 January 2021

\section{References}

1. Plastics the Facts 2019 An analysis of European plastics production, demand and waste data; 2019. https://www.plasticseurope.org/en/resou rces/market-data.

2. Marchal V, van Dellink RDV, Clapp C, Château J, Eliza Lanzi BMJ van V. Climate change. In: OECD Environmental Outlook to 2050; 2011.

3. Spierling S, Knüpffer E, Behnsen H, Mudersbach M, Krieg H, Springer S, et al. Bio-based plastics - a review of environmental, social and economic impact assessments. J Clean Prod. 2018;1 (185):476-91.

4. Anderson AJ, Dawes EA. Occurrence, metabolism, metabolic role, and industrial uses of bacterial Polyhydroxyalkanoates, microbiological reviews, vol. 54. Washington: American Society for Microbiology (ASM); 1990. p. 450.

5. Vu DH, Åkesson D, Taherzadeh MJ, Ferreira JA. Recycling strategies for polyhydroxyalkanoate-based waste materials: an overview. Bioresour Technol. 2020;298:122393.

6. Han J, Hou J, Liu H, Cai S, Feng B, Zhou J, et al. Wide distribution among halophilic archaea of a novel polyhydroxyalkanoate synthase subtype with homology to bacterial type III synthases. Appl Environ Microbiol. 2010;76(23):7811-9.

7. Kynadi AS, Suchithra TV. Polyhydroxyalkanoates : biodegradable plastics for environmental conservation industrial \& environmental biotechnology. In: Patra JK, editors. Studium Press (India) Pvt. Ltd.; 2014.

8. Meng DC, Shen R, Yao H, Chen JC, Wu Q, Chen GQ. Engineering the diversity of polyesters. Curr Opin Biotechnol. 2014;29:24-33.

9. Abid S, Raza ZA, Hussain T. Production kinetics of polyhydroxyalkanoates by using Pseudomonas aeruginosa gamma ray mutant strain EBN-8 cultured on soybean oil. 3 Biotech. 2016;6(2):142.

10. Hoefer P. Activation of polyhydroxyalkanoates: Functionalization and modification. Front Biosci. 2010;15(1):93-121.

11. Manangan T, Shawaphun S. Quantitative extraction and determination of polyhydroxyalkanoate accumulated in Alcaligenes latus dry cells. ScienceAsia. 2010;36(3):199-203. 
12. Anis SNS, Md lqbal N, Kumar S, Amirul AA. Effect of different recovery strategies of $\mathrm{P}(3 \mathrm{HB}-\mathrm{CO}-3 \mathrm{HHx})$ copolymer from Cupriavidus necator recombinant harboring the PHA synthase of Chromobacterium sp. USM2. Sep Purif Technol. 2013;102:111-7.

13. Kourmentza C, Plácido J, Venetsaneas N, Burniol-Figols A, Varrone C, Gavala HN, et al. Recent advances and challenges towards sustainable polyhydroxyalkanoate (PHA) production. Bioengineering. 2017:4(2):55

14. Aramvash A, Gholami-Banadkuki N, Moazzeni-Zavareh F, Hajizadeh-Turchi S. An environmentally friendly and efficient method for extraction of PHB biopolymer with non-halogenated solvents. J Microbiol Biotechnol J Microbiol Biotechnol. 2015;11:1936-43.

15. Fei T, Cazeneuve $S$, Wen $Z, W u L$, Wang $T$. Effective recovery of poly- $\beta$ hydroxybutyrate (PHB) biopolymer from Cupriavidus necator using a novel and environmentally friendly solvent system. Biotechnol Prog. 2016;32(3):678-85.

16. Pacheco MA, Marshall CL. Review of dimethyl carbonate (DMC) manufacture and its characteristics as a fuel additive. Energy Fuels. 1997;11(1):2-29.

17. Tundo P, Selva M. The chemistry of dimethyl carbonate. Acc Chem Res. 2002;35(9):706-16.

18. Romano IU, Muzio N Di. United States Patent (19); 1982. p. 4-6.

19. Kanegsberg B, Kanegsberg E. Handbook for critical cleaning. Handbook for Critical Cleaning: CRC Press; 2011.

20. Pérez-Rivero C, López-Gómez JP, Roy I. A sustainable approach for the downstream processing of bacterial polyhydroxyalkanoates: state-of-theart and latest developments. Biochem Eng J. 2019;150:107283.

21. Comeau Y, Hall KJ, Oldham WK. Determination of poly-3-hydroxybutyrate and poly-3-hydroxyvalerate in activated sludge by gas-liquid chromatography. Appl Environ Microbiol. 1988;54(9):2325-7.

22. Hahn SK, Chang YK, Kim BS, Lee KM, Chang HN. The recovery of poly(3hydroxybutyrate) by using dispersions of sodium hypochlorite solution and chloroform. Biotechnol Tech. 1993;7(3):209-12.

23. Porter M, Yu J. Crystallization kinetics of poly(3-hydroxybutyrate) granules in different environmental conditions. J Biomater Nanobiotechnol. 2011;2(3):301.

24. Fiorese ML, Freitas F, Pais J, Ramos AM, De Aragão GMF, Reis MAM. Recovery of polyhydroxybutyrate (PHB) from Cupriavidus necator biomass by solvent extraction with 1,2-propylene carbonate. Eng Life Sci. 2009;9(6):454-61.

25. Li R, Zhang H, Qi Q. The production of polyhydroxyalkanoates in recombinant Escherichia coli. Bioresour Technol. 2007;98(12):2313-20.

26. Lee SY, Chang HN. Production of poly(hydroxyalkanoic acid). In: Advances in biochemical engineering/biotechnology. Berlin: Springer; 1995. p. 27-58.

27. Choi J, Lee SY. Efficient and economical recovery of poly(3-hydroxybutyrate) from recombinant Escherichia coli by simple digestion with chemicals. Biotechnol Bioeng. 1998;62(5):546-53.

28. Liu F, Li W, Ridgway D, Gu T, Shen Z. Production of poly- $\beta$ hydroxybutyrate on molasses by recombinant Escherichia coli. Biotechnol Lett. 1998;20(4):345-8.

29. Righi S, Baioli F, Samorì C, Galletti P, Tagliavini E, Stramigioli C, et al. A life cycle assessment of poly-hydroxybutyrate extraction from microbial biomass using dimethyl carbonate. J Clean Prod. 2017;168:692-707.

30. Khoo HH, Isoni V, Sharratt PN. LCl data selection criteria for a multidisciplinary research team: LCA applied to solvents and chemicals. Sustain Prod Consum. 2018;16:68-87.

31. McChalicher CWJ, Srienc F, Rouse DP. Solubility and degradation of polyhydroxyalkanoate biopolymers in propylene carbonate. AIChE J. 2010;56(6):1616-25.

32. Samorì C, Basaglia M, Casella S, Favaro L, Galletti P, Giorgini L, et al. Dimethyl carbonate and switchable anionic surfactants: two effective tools for the extraction of polyhydroxyalkanoates from microbial biomass. Green Chem. 2015;17(2):1047-56.

33. Domínguez-Díaz M, Meneses-Acosta A, Romo-Uribe A, Peña C, Segura D, Espin G. Thermo-mechanical properties, microstructure and biocompatibility in poly- $\beta$-hydroxybutyrates (PHB) produced by OP and OPN strains of Azotobacter vinelandii. Eur Polym J. 2015;63:101-12.

34. Lauzier C, Revol JF, Marchessault RH. Topotactic crystallization of isolated poly( $\beta$-hydroxybutyrate) granules from Alcaligenes eutrophus. FEMS Microbiol Lett. 1992;103(2-4):299-310.
35. Jüttner RR, Lafferty RM, Knackmuss HJ. A simple method for the determination of poly- $\beta$-hydroxybutyric acid in microbial biomass. Eur J Appl Microbiol. 1975;1(3):233-7.

36. Wong PTT, Wong RK, Caputo TA, Godwin TA, Rigas B. Infrared spectroscopy of exfoliated human cervical cells: evidence of extensive structural changes during carcinogenesis. Proc Natl Acad Sci U S A. 1991;88(24):10988-92.

37. Fleming I, Williams D. Spectroscopic methods in organic chemistry. London: McGraw-Hill; 2019.

38. Hedrick DB, Nivens DE, Stafford C, White DC. Rapid differentiation of archaebacteria from eubacteria by diffuse reflectance Fouriertransform IR spectroscopic analysis of lipid preparations. J Microbiol Methods. 1991;13(1):67-73.

39. Zeroual W, Choisy C, Doglia SM, Bobichon H, Angiboust JF, Manfait M. Monitoring of bacterial growth and structural analysis as probed by FT-IR spectroscopy. BBA Mol Cell Res. 1994;1222(2):171-8.

40. Nelson W, Sperry J. UV resonance and raman spectroscopic detection and identification of bacteria and other microorganims. In: Nelson WH, editor. Modern techniques for rapid microbiological analysis. New York: VCH Publishers; 1991. p. 97-143.

41. Kahar P, Agus J, Kikkawa Y, Taguchi K, Doi Y, Tsuge T. Effective production and kinetic characterization of ultra-high-molecular- weight poly[(R)-3-hydroxybutyrate] in recombinant Escherichia coli. Polym Degrad Stab. 2005;87(1):161-9.

42. Zhang H, Obias V, Gonyer K, Dennis D. Production of polyhydroxyalkanoates in sucrose-utilizing recombinant Escherichia coli and Klebsiella strains. Appl Environ Microbiol. 1994;60(4):1198-205.

43. Kusaka S, Abe H, Lee SY, Doi Y. Molecular mass of poly[(R)-3-hydroxybutyric acid] produced in a recombinant Escherichia coli. Appl Microbiol Biotechnol. 1997;47(2):140-3.

44. Jiang G, Johnston B, Townrow DE, Radecka I, Koller M, Chaber P, et al. Biomass extraction using non-chlorinated solvents for biocompatibility improvement of polyhydroxyalkanoates. Polymers (Basel). 2018;10(7):731

45. Dietrich K, Dumont MJ, Del Rio LF, Orsat V. Producing PHAs in the bioeconomy - towards a sustainable bioplastic. Sustain Prod Consum. 2017;9:58-70.

46. Narodoslawsky M, Shazad K, Kollmann R, Schnitzer H. LCA of PHA production-Identifying the ecological potential of bio-plastic. Chem Biochem Eng Q. 2015;29(2):299-305.

47. Righi S, Baioli F, Samorì C, Galletti P, Tagliavini E, Stramigioli C, et al. A life cycle assessment of poly-hydroxybutyrate extraction from microbial biomass using dimethyl carbonate. J Clean Prod. 2017;1(168):692-707.

48. Rosenbaum RK, Bachmann TM, Gold LS, Huijbregts MAJ, Jolliet O, Juraske $\mathrm{R}$, et al. USEtox-The UNEP-SETAC toxicity model: Recommended characterisation factors for human toxicity and freshwater ecotoxicity in life cycle impact assessment. Int J Life Cycle Assess. 2008;13:532.

49. Cristóbal J, Matos CT, Aurambout JP, Manfredi S, Kavalov B. Environmental sustainability assessment of bioeconomy value chains. Biomass Bioenerg. 2016:89:159-71.

50. Martínez V, Herencias C, Jurkevitch E, Prieto MA. Engineering a predatory bacterium as a proficient killer agent for intracellular bio-products recovery: the case of the polyhydroxyalkanoates. Sci Rep. 2016;6:24381.

51. Pais J, Farinha I, Freitas F, Serafim LS, Martínez V, Martínez JC, et al. Improvement on the yield of polyhydroxyalkanotes production from cheese whey by a recombinant Escherichia coli strain using the proton suicide methodology. Enzyme Microb Technol. 2014;55:151-8.

52. Lonare AA, Patel SR. Antisolvent crystallization of poorly water soluble drugs. Int J Chem Eng Appl. 2013;4(5):337-41.

53. Giulietti M, Bernardo A. Crystallization by antisolvent addition and cooling. In: Andreeta MRB, editor. Crystallization—science and technology; 2012. p. 379-96.

54. Braunegg G, Sonnleitner B, Lafferty RM. A rapid gas chromatographic method for the determination of poly- $\beta$-hydroxybutyric acid in microbial biomass. Eur J Appl Microbiol Biotechnol. 1978;6:29-37.

55. The R Foundation. R: the R Project for Statistical Computing; 2018. https:// www.r-project.org/. Accessed 13 May 2020.

56. Stasinopoulos DM, Rigby RA. Generalized additive models for location scale and shape (GAMLSS) in R. J Stat Softw. 2007;23(7):1-46. 
57. Akita S, Einaga Y, Miyaki Y, Fujita H. Solution properties of poly(D- $\beta$ hydroxybutyrate). 1. Biosynthesis and characterization. Macromolecules. 1976;9(5):774-80.

58. ISO. 14040: environmental management-life cycle assessment-principles and framework. Geneva: International organization for standardization; 2006.

59. ISO. 14044: environmental management-Life cycle assessmentRequirements and guidelines. Geneva: International Organization for Standardization; 2006

60. Breil C, Meullemiestre A, Vian M, Chemat F. Bio-based solvents for green extraction of lipids from oleaginous yeast biomass for sustainable aviation biofuel. Molecules. 2016;21(2):1-14.

61. Holbrook MT. Chloroform. Kirk-Othmer Encycl Chem Technol. 2000;6:279-90.

62. Righi S, Bandini V, Fabbri D, Cordella M, Stramigioli C, Tugnoli A. Modelling of an alternative process technology for biofuel production and assessment of its environmental impacts. J Clean Prod. 2016;2016(122):42-51.
63. Guinée JB. Selection of impact categories and classification of LCI Results To Impact Categories. In: Hauschild MHM, editor. Life cycle impact assessment LCA compendium — the complete world of life cycle assessment. Dordrecht: Springer; 2015. p. 17-37.

64. European Commission - Joint Research Centre—Institute for Environment and Sustainability. International Reference Life Cycle Data System (ILCD) Handbook — General guide for Life Cycle Assessment-Detailed guidance. First Edit. Publications Office of the European Union; 2010. 417

65. The European Commission. European Platform on Life Cycle Assessment; 2017. https://eplca.jrc.ec.europa.eu/ilcd.html. Accessed 13 May 2020.

\section{Publisher's Note}

Springer Nature remains neutral with regard to jurisdictional claims in published maps and institutional affiliations.
Ready to submit your research? Choose BMC and benefit from:

- fast, convenient online submission

- thorough peer review by experienced researchers in your field

- rapid publication on acceptance

- support for research data, including large and complex data types

- gold Open Access which fosters wider collaboration and increased citations

- maximum visibility for your research: over $100 \mathrm{M}$ website views per year

At BMC, research is always in progress.

Learn more biomedcentral.com/submissions 